\title{
Relapsing Transient Neonatal Diabetes Mellitus due to ABCC8 Mutation
}

Poovazhagi $\mathbf{V}^{*}$ and Thangavelu S

Thanjavur Medical College, Department of Pedaitrics, Govt Raja Mirasdar Hospital, Anna Salai, Thanjavur, TamilNadu, India

*Corresponding author: Poovazhagi V, Associate professor of pediatrics, Thanjavur Medical College, Department of Pedaitrics, Govt Raja Mirasdar Hospital, Anna Salai, Thanjavur, TamilNadu, India, Tel: 044-9840033020; E-mail: poomuthu@yahoo.com

Received date: Sep 03, 2014, Accepted date: Oct 06, 2014, Published date: Oct 15, 2014

Copyright: (c) 2014 Poovazhagi V, et al., This is an open-access article distributed under the terms of the Creative Commons Attribution License, which permits unrestricted use, distribution, and reproduction in any medium, provided the original author and source are credited.

\begin{abstract}
Neonatal diabetes mellitus with onset in the first six months of life is predominantly monogenic. Genetic evaluation of such infants is mandatory irrespective of the diabetic duration. Management of sulphonylurea responsive mutation induced diabetes is rewarding as it improves the metabolic control without exogenous insulin lifelong. Here we present a child with neonatal onset diabetes who remitted at 10 months of age and relapsed at 10 years, 8 months of age and was effectively switched over to oral sulphonylurea following identification of mutation in the ABCC8- SUR1 subunit of the K-ATP channel.
\end{abstract}

Keywords: Neonatal diabetes; ABCC8 mutation; Relapse

\section{Case Report}

A $3 \frac{1}{2}$ month old female infant presented with history of polyuria for 2 days duration. She developed breathlessness and fever following which she was brought to our hospital. Mother had noted lethargy for 2 days. She was the $1^{\text {st }}$ born of non-consanguineous parents with uneventful neonatal period. She was delivered as a term baby with a birth weight of $2250 \mathrm{gm}$. She had attained social smile at 12 weeks [1]. She weighed $2.8 \mathrm{~kg}$, was lethargic, acidotic, dehydrated and febrile. Her blood glucose at admission was $484 \mathrm{mg} / \mathrm{dl}$. Her blood gases revealed wide anion gap metabolic acidosis and her urine was tested positive for ketones and glucose. She was diagnosed to have Diabetic Keto acidosis and was started on treatment as per unit protocol for DKA. She received Insulin infusion for 12 hours and following her recovery from acidosis she was started on subcutaneous insulin. Family history revealed both the maternal and paternal grandmothers to be diabetic on oral hypoglycemic drugs. Mother and the Father were found to be euglycemic. She did not have any dysmorphic features [2]. Her C peptide value was $0.2 \mathrm{ng} / \mathrm{ml}$ (negligible). HBAlc was very high $10 \%$. Her liver enzymes were normal. Skeletal survey revealed normal study. Serum T3 T4 and TSH were within normal limits. Ultra sonogram abdomen was reported normal. TORCH screening was not contributory. She was diagnosed to have diabetes mellitus and was stabilized on intermediate acting insulin given 12 hourly she was started on 4 units of intermediate acting insulin and discharged home. On follow up she had a fair blood glucose control. She was on insulin for 7 months and with decreasing blood glucose values insulin had to be tapered and stopped. Her repeat HBAlc after 4 months was $7.2 \%$ [3].

Her blood glucose values were followed up every 6 months and were within normal limits. Her growth and development was monitored to be normal. She was treated for iron deficiency anemia at the age of 3 years and was followed up without any significant medical illness. She was followed up annually for 9 years after remission. At the age of 10 years 8 months she developed polyuria and polydipsia and her blood glucose was found to be $418 \mathrm{mg} / \mathrm{dl}$. Her c peptide was 1.83 $\mathrm{ng} / \mathrm{ml}$ (Normal). She was diagnosed to have relapsed with diabetes and was re started on Insulin [4].

During follow up her father was diagnosed with Type 2 diabetes. Child was restarted on insulin at a dose of 1.2 unit $/ \mathrm{kg} /$ day. Her HBA1c was $11.2 \%$. Her lipid profile was within normal limits. She was tested to be negative for GAD and Insulin antibodies. Child was subjected to genetic analysis. Test methodology was sequence analysis, coding and flanking intronic regions of the ABCC8, KCNJ11 and INS genes (U63421, L78208, NM_000525.3 and NM_000207.2) of leucocyte DNA sample.This identified a novel heterozygous ABCC8 mutation in the child. The mutation details are as follows. Gene: ABCC8, Location: Exon 28, DNA Description: c.3527A $>$ G, Protein Description: p.Tyr1176Cys (p.Y1176C). Sequence analysis of exon 28 of the ABCC8 gene (U63421 and L78208) of the father and the mother did not reveal any mutation. She was the only child of the family. The tyrosine at codon 1176 is highly conserved across species and mutation testing in her parents has shown that the p.Y1176C mutation has arisen de novo. This result confirms a diagnosis of transient neonatal diabetes due to a mutation in the SUR1 subunit of the K-ATP channel. She was started on oral sulphonylurea as per hospital transfer protocol and was successfully transferred to oral glibenclamide and progressively the HBA1c values declined to $7 \%$. Her growth and development is normal. She is on oral glibenclamide $5 \mathrm{mg}$ twice daily and is maintaining euglycemia. Child is now 14 years of age and is followed up regularly [5].

\section{Discussion}

Diabetes mellitus with onset in the first 6 months of life is predominantly monogenic [1-3]. The incidence of neonatal diabetes mellitus varies from 1 in 89,000 to 1 in 400000 live births [4]. Neonatal diabetes mellitus is of two types transient neonatal DM (TNDM) and permanent Neonatal DM (PNDM).

Transient Neonatal diabetes (TNDM) usually presents in the first few weeks of life and last for at least 2 weeks and usually resolves by 12 weeks. In contrast to the western literature, Indian literature shows that Transient neonatal diabetes accounts only for $5 \%$ of all neonatal diabetes mellitus $[5,6]$. Chromosome $6 \mathrm{q}$ related mutations followed by ABCC8 (SUR) mutations and KCNJ11 account for most of TNDM. 
Intra uterine growth retardation, hyperglycemia, dehydration and lack of ketoacidosis are cardinal features of TNDM. However the child we described presented with features of Keto acidosis. Though transient in about $50 \%$ of children, diabetes recurs in the pediatric age group or in the early adult age group. Children in remission need to be followed up annually for hyperglycemia [6].

Neonatal diabetes need to be evaluated with a clinical examination, dysmorphic features, anthropometry, developmental assessment, thyroid evaluation, liver enzymes and skeletal survey. This has to be followed by $\mathrm{C}$ peptide levels to assess the insulin secretion status. GAD and other auto antibodies to differentiate immune mediated diabetes mellitus may be done if the infant is beyond six months at presentation. Genetic evaluation of all infants with onset of diabetes at or less than 6 months of age is mandatory. Subsequent management strategy with lifelong insulin or sulphonylurea will be decided by the genetic evaluation reports [5]. Since the genetic evaluation is critical for deciding the mode of therapy all infants with onset of DM before 6 months of age should undergo genetic testing to identify the mutation.

Relapse can be treated with either dietary modification or insulin therapy or with oral glibenclamide if found to have sulphonylurea responsive monogenic diabetes. Neonatal diabetes mellitus can be transient with lifelong remission, some can go in for remission for variable period of time only to recur in the later part of life and some infants continue to have hyperglycemia. Nearly $50 \%$ of children with neonatal diabetes relapse in late childhood or early adulthood [7]. Infants with neonatal DM can be successfully shifted to oral sulphonylurea therapy if they have sulphonylurea responsive diabetes mellitus. This conversion can be done at any age irrespective of the duration of diabetes [8]. More than $90 \%$ of these $\mathrm{K}_{\mathrm{ATP}}$ mutations respond to sulphonylurea either at the onset or during relapse [8]. However earlier institution of sulphonylurea is preferred over regular insulin therapy as the drug therapy is associated with good neurological recovery. Any sulfonylurea should be as effective as any other in treating the diabetes. Gliclazide only binds to SUR1 (pancreas/neurons) whereas glibenclamide binds to cardiac and muscle (SUR2A) as well. Glibenclamide is safe and the reported side effects include skin rashes and diarrhea. Rarely reported are anemia, thrombocytopenia and liver dysfunction $[7,8]$. The required dose of sulphonylurea in TNDM relapse is much less in comparison to the PNDM children. The starting dose can be $0.05 \mathrm{mg} / \mathrm{kg} /$ day divided into two doses and titrated according to the response.

The child described here was diagnosed to have diabetes in the year 2001 and remitted at 7 months and was free of therapy till 10 years of age. She relapsed into diabetes without DKA and was restarted on insulin and then changed over to sulphonylurea. Though this child underwent genetic evaluation only during the relapse it is ideal to perform genetic evaluation at the earliest. Genetic evaluation should not be denied in view of the age of the child if older [9]. Switch over from insulin to oral sulphonylurea can be done as a rapid inpatient procedure or through a slow put patient procedure. Oral therapy has been found to be safe in infants and children despite requiring much higher doses [9].

\section{Points to remember}

- All infants with diabetes mellitus with onset at less than 6 months have to undergo genetic evaluation for monogenic diabetes

- Infants with transient form of neonatal diabetes need to be followed annually for relapse

- Change over from insulin to oral sulphonylurea can be done even during relapse if diagnosed to have sulphonylurea responsive mutation. Such change over to oral therapy is found to be safe and effective

\section{Acknowledgement}

Authors like to acknowledge the molecular genetics lab, Exeter, UK for providing the genetic reports of the family free of cost.

\section{References}

1. Hattersley A, Bruining J, Shield J, Njolstad P, Donaghue K (2009) ISPAD Clinical Practice Consensus Guidelines 2009 Compendium. The diagnosis and management of monogenic diabetes in children and adolescent. Pediatric Diabetes 10: 33-42.

2. Greeley SA, Naylor RN, Philipson LH, Bell GI (2011) Neonatal diabetes: an expanding list of genes allows for improved diagnosis and treatment. Curr Diab Rep 11: 519-532.

3. Iafusco D, Stazi MA, Cotichini R, Cotellessa M, Martinucci ME, et al. (2002) Permanent diabetes mellitus in the first year of life. Diabetologia 45: 798-804.

4. Jeha GS, Venkatesh MP, Edelen RC, Kienstra KA, Karaviti L, et al. (2005) Neonatal diabetes mellitus: patient reports and review of current knowledge and clinical practice. J Pediatr Endocrinol Metab 18: 1095-1102.

5. Polak M, Cavé H (2007) Neonatal diabetes mellitus: a disease linked to multiple mechanisms. Orphanet J Rare Dis 2: 12.

6. Jahnavi S, Poovazhagi V, Mohan V, Bodhini D, Raghupathy P, et al. (2013) Clinical and molecular characterization of neonatal diabetes and monogenic syndromic diabetes in Asian Indian children. Clin Genet 83: 439-445.

7. Flagnan, Sarah. Transient neonatal diabetes. Diabedia 41040851198 rev 23.

8. Pearson ER, Flechtner I, Njølstad PR, Malecki MT, Flanagan SE, et al. (2006) Switching from insulin to oral sulfonylureas in patients with diabetes due to Kir6.2 mutations. N Engl J Med 355: 467-477.

9. Mohamadi A, Clark LM, Lipkin PH, Mahone EM, Wodka EL, et al. (2010) Medical and developmental impact of transition from subcutaneous insulin to oral glyburide in a 15-yrold boy with neonatal diabetes mellitus and intermediate DEND syndrome: extending the age of KCNJ11 mutation testing in neonatal DM. Pediatr Diabetes 11: 203-207. 